\title{
Experimental and theoretical modeling of Fe-, Co-, Cu-, Mn-based electrocatalysts for oxygen reduction
}

\author{
Helmut Tributsch*, Ulrike I. Koslowski, Iris Dorbandt \\ Hahn-Meitner-Institut Berlin GmbH, Glienicker Str. 100, D-14109 Berlin
}

Abstract:

Experience gained during efforts towards optimization of noble-metal-free electrocatalysts for oxygen reduction is simultaneously used to understand the chemical and morphological necessities for inducing efficient multi-electron transfer catalysis. The analysis of many preparative experimental steps between the moderately performing metal porphyrines and the highly efficient transition metal- and sulfur- containing pyrolised catalyst material contributes to the following model of the catalyst: The metals function enclosed in nitrogen or graphitic environment where they are shielded against irreversible oxidation. The metals can be exchanged but are not identical in their efficiency. Higher efficiency is achieved, when the function of a binary reaction center is warranted. The carbonization of the environment is critical and provides intercalated metal centers and attached metal complexes in graphite environment for interaction with the nitrogen-chelated partner center in the simultaneously obtained graphene layers. Three alternatives for the binary catalytic center are presented and their relevance discussed on the basis of EXAFS, RAMAN, EPR, Mössbauer and X-ray spectroscopy. A parallel is drawn with the cytochrome oxidase oxygen reduction catalysis, which is proposed to proceed according to roughly the same mechanism.

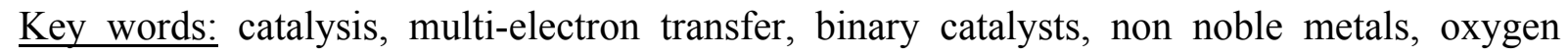
reduction 
Introduction:

There is wide agreement that mass production of fuel cells for transportation and domestic uses will lead to scarcity and cost-increase of Pt-based catalysts. It is, therefore, reasonable to start early with research aimed at replacement of Pt by more abundant transition metals such as $\mathrm{Fe}, \mathrm{Co}, \mathrm{Cu}, \mathrm{Mn}$, Mo for multielectron transfer catalysis[1]. In the case of oxygen reduction it is well known that nature has solved the catalytic problem using a $\mathrm{Fe}-\mathrm{Cu}$ center. It has been pointed out that in order to protect these transition metals from irreversibly reacting with oxygen, nature has evolved strategies to chemically protect and tailor their environment. They are chelated with nitrogen (porphyrins, heme groups), possible bonding sites are saturated with strongly bonding $\mathrm{CN}$ - or CO-groups and special electron exchange mechanisms are involved. Ferredoxins $\left(\mathrm{Fe}_{4} \mathrm{~S}_{4}, \mathrm{Fe}_{2} \mathrm{~S}_{2}\right)$, for example, are linked to cysteine bridges for electron transfer, which do not engage in close to equilibrium electron exchange processes. These amino acids do not contain double bonds or aromatic rings for easy electron exchange but they are able to a restructuring of electron distribution upon extraction of an electron from the binding thiol-sulfur. [2]

All such molecular characteristics contribute to a quite specific property of multi-electron transfer catalysts based on abundant transition metals. They allow the metal centers to exchange their valence state while suppressing their tendency to irreversibly react with oxygen molecules. When transferring concepts from biology to technology it was discovered that metal center containing organic macromolecules cannot be adapted and utilized for technical application. More stable and durable materials have to be engineered.

There is a long history of efforts in transferring biological metal centers to practical technical use by restructuring their carbon based environment. [3-6]. Metal porphyrins were carbonized at elevated temperatures $\left(500{ }^{\circ} \mathrm{C}-900{ }^{\circ} \mathrm{C}\right)$ with the aim of maintaining the approximate 
structure of the center while converting the molecular surrounding into carbon [7-11]. Other efforts were aimed at synthesizing $\mathrm{FeN}_{\mathrm{x}}$-centers by reacting a transition metal salt, which has been impregnated onto a carbon support, at elevated temperature in the presence of $\mathrm{NH}_{3}$ [1213]. Currently, significant efforts are on the way to tailor and understand non-noble metal catalysts on the basis of nano-structured or thin layer carbon while replacing Platinum [14$16]$.

We heated metal prophyrins together with iron oxalate (as foaming agent) and sulfur compounds to obtain a fine-structured catalyst for oxygen reduction [17-18]. A remarkable activity of the catalytic metal centers $(\mathrm{Fe} / \mathrm{Co})$ was found, which, when referred to the metal weight, even surpassed Pt by a factor of 10 . However, the concentration of active sites remained low. In order to increase it by appropriate methods of synthesis it appears to be necessary to obtain more information on the chemical nature of the center involved in multielectron transfer. This publication is intended as a contribution towards this aim.

For this purpose of discussing models for catalytic centers it is necessary to consider theoretical concepts for multi-electron transfer. For energy efficient multi-electron transfer catalysis it is required that the overall electron transfer becomes essentially self organized. Formally, individual electron transfer steps are related to each other, with the consequence, that the set of corresponding equations can be reduced to a single one, which is then reflecting improved, multi-step, electron transfer. The theoretical formalism for such an approach has been discussed phenomenological in [19-20]. The conclusions were used as a guide line to understand and to tailor appropriate models of binary catalytic centers. Basically, the first electron transfer is triggering a molecular change, which is facilitating the transfer of the second electron. This transfer facilitates, via an additional change, the transfer of the third, and this the transfer of the fourth electron. Binary centers of abundant transition metals (Fe, $\mathrm{Co}, \mathrm{Cu}, \mathrm{Mn}$ ) can do that, but individual centers can not get involved in such a reaction, because they can not accommodate four electrons towards a coordinated mechanism of multi- 
electron transfer for oxygen reduction. This is not a matter of electron supply, but a matter of energy efficiency, which is involved in multi-electron transfer, since the thermodynamic formula for electron transfer suggests that several electrons are transferred at a similar most favorable electrochemical potential. If multi-electron transfer in electrochemistry would be limited by electron supply only, any metal electrode could catalyse multi-electron transfer favourably. It is however known that this is not the case.

\section{Experimental:}

Preparation of the CoTMPP/FeC $\mathrm{O}_{4} / \mathrm{S}$ catalyst (called $\mathrm{Co} / \mathrm{Fe} / \mathrm{S}$-catalyst). -

A mixture of $1.6 \mathrm{~g}$ (1 molar equivalent) 5,10,15,20-tetrakis(4-methoxyphenyl)-21H,23Hporphyrin cobalt (II) (94\%, Acros), $8.2 \mathrm{~g}$ (22 molar equivalents) iron (II) oxalate dihydrate ( $\geq$ $99 \%$, Riedel de Haën) and 0.5 g (8 molar equivalents) sulfur (99,99+\%, Aldrich) was introduced into a quartz glass tube and heated under constant flow of nitrogen in a split-hinge furnace. The first heating step was performed from room temperature to $450{ }^{\circ} \mathrm{C}$, the holding time was $30 \mathrm{~min}$. The second heating step was performed from $450{ }^{\circ} \mathrm{C}$ to $750{ }^{\circ} \mathrm{C}$ with a holding time of $120 \mathrm{~min}$. The heating rate was $300{ }^{\circ} \mathrm{C} / \mathrm{h}$. After cooling under inert gas atmosphere, the sample was introduced into $1 \mathrm{M}$ hydrochloric acid and stirred for 12-24 $\mathrm{h}$. After filtration and washing with $2 \mathrm{~L}$ of water, the black catalyst powder was dried at $80{ }^{\circ} \mathrm{C}$ in a drying oven. Yields from 7 to 8 w.t.\% have been obtained.

Following this procedure also $\mathrm{Cu}-, \mathrm{Mn}-$ and Fe-porphyrins were used in combination with iron (II) oxalate dihydrate (other metal oxalates were not used in this study because they significantly affected the morphology of the catalyst). For convenience, 5,10,15,20-tetrakis(4methoxyphenyl)-21H,23H-porphyrin is called TMPP and 5,10,15,20-tetratolyl-21H,23Hporphyrin is called TTP. 


\section{Electrochemical measurements. -}

The electrochemical experiments were carried out at room temperature in a three-electrodesystem with a platinum wire as counter electrode and with an $\mathrm{Hg} / \mathrm{Hg}_{2} \mathrm{SO}_{4} / 0.5 \mathrm{M} \mathrm{H} \mathrm{H}_{2} \mathrm{SO}_{4}$ electrode as reference electrode. To prepare the working electrode $1 \mathrm{mg}$ of catalyst was suspended in $200 \mu \mathrm{l}$ of $0.2 \%$ Nafion solution in water/ethanol 1:1. $5 \mu \mathrm{l}$ of this suspension were dropped onto a $0.071 \mathrm{~cm}^{2}$ glassy carbon rod, which was embedded in a Teflon cylinder. The amount of catalyst on the disc was consequently $0.35 \mathrm{mg} / \mathrm{cm}^{2}$. After drying at $60{ }^{\circ} \mathrm{C}$, a homogeneous catalyst layer was formed on the electrode surface. The homogeneity of the surface has been controlled by an optical microscope.

The catalysts have been activated by cyclic voltammetry in $\mathrm{N}_{2}$ saturated $0.5 \mathrm{M} \mathrm{H}_{2} \mathrm{SO}_{4}$, rotating disk electrode (RDE) experiments have been performed with a sweep rate of 0.3 $\mathrm{V} / \mathrm{min}$ in the same $\mathrm{O}_{2}$ saturated electrolyte at 100, 200, 400, 900, 1600 and $2500 \mathrm{rpm}$. Oxygen was passed over the electrolyte during the RDE measurement. The Koutecky-Levich equation was used to determine the kinetic current. Data are presented in Tafel plots just to compare different materials. It should be mentioned that absolute values determined by this method con only be discussed carefully because errors can become significant at low voltages [21]. All potentials are reported versus NHE and current densities were calculated by division over the electrode surface area.

\section{Thermogravimetric measurements. -}

Thermogravimetric measurements were carried out in a NETZSCH Simultaneous Thermal Analyzer STA 409C connected with a quadrupole mass spectrometer via skimmer coupling system. Thermogravimetric changes could be detected simultaneously as ionized gas species. The measurements were performed in an $\mathrm{Al}_{2} \mathrm{O}_{3}$ sample crucible under continuous flow of $\operatorname{argon}\left(80 \mathrm{~cm}^{-3} / \mathrm{min}\right)$ with a heating rate of $10 \mathrm{~K} / \mathrm{min}$. 


\section{Raman spectroscopy. -}

Raman spectra were measured using a LabRam spectrometer by JobinYvon at room temperature. For excitation $632 \mathrm{~nm}$ red line of $\mathrm{He} / \mathrm{Ne}$ laser was used. Samples have been pressed in $\mathrm{KBr}$ pellet. By means of microscope (Olympus $\mathrm{BX}$ ), the surface of sample has been focussed. In order to separate Raman and Rayleigh scattering, notch filter and monochromator have been used. Finally, a CCD camera has detected the Raman bands. The Raman spectra have been unfolded by Gauss and/or Lorentz procedure. The obtained characteristic Raman peaks for carbon blacks have been interpreted and analysed by using the work of Tuinstra and König. [22]

\section{Electron paramagnetic resonance spectroscopy.-}

Measurements of electron paramagnetic resonance (EPR) were performed at a temperature of $5 \mathrm{~K}$ using a BRUKER ELEXSYS 580 spectrometer which operated at $X$-band frequencies ( 9.5 GHz) in the continuous-wave mode. Spectra were recorded with a modulation amplitude of $5 \mathrm{G}$, a modulation frequency of $100 \mathrm{kHz}$ and a microwave power of $\sim 1 \mathrm{~mW}$ in a range of 100 to $7900 \mathrm{G}$.

Extended $x$-ray absorption fine structure spectroscopy. -

EXAFS measurements were carried out at BESSY II (Berlin) at beamline KMC-2 using a double crystal monochromator. Experiments were performed with powder samples at room temperature in a geometry allowing for parallel measurements of transmission and fluorescence signals. Data was recorded at the K-edges of cobalt and iron, respectively. For analysis fitting of the spectra with theoretical reference data obtained by the ab-initio multiple scattering algorithm FEFF was performed [23]. The theoretical standards used for the fitting of the first (nitrogen) coordination shell were the structural parameters of 5,10,15,20,- 
Tetrakis-(2-methoxy-phenyl)-porphyrin-Co(II), the experimental standards used were $\mathrm{Co}_{3} \mathrm{O}_{4}$, $\mathrm{CoO}, \mathrm{CoS}, \mathrm{CoSO}_{4}$ and metallic $\mathrm{Co}$. Results are presented as magnitude and imaginary part of the Fourier transformation without k-weighting or phase-correction applied.

EXAFS data showed that exchange of metals between nitrogen coordination sites and the oxalate was possible due to the heat treatment of the samples.

\section{Mößbauer spectroscopy. -}

${ }^{57} \mathrm{Fe}-\mathrm{Mößbauer}$ spectra were measured at room temperature using a standard transmission setup in constant acceleration mode with a ${ }^{57} \mathrm{Co} / \mathrm{Rh}$-source. Spectra are displayed with reference to $\alpha-{ }^{57} \mathrm{Fe}$. Analysis was performed by least-square fitting of Lorentzian curves.

\section{Analytical tools}

For all catalyst materials metal content were obtained by neutron activation analysis (NAA).

$\underline{\text { Results: }}$

After mixing transition metal porphyrins with iron oxalate and sulfur, they are heated up to $600^{\circ}-800^{\circ} \mathrm{C}$. Most of the metal organic precursor is carbonized while part of the matter is lost to the gas phase.

This process can be followed by thermogravimetry coupled with a mass spectrometer (fig. 1). At $200{ }^{\circ} \mathrm{C}$ the release of crystal water of $\mathrm{FeC}_{2} \mathrm{O}_{4} * 2 \mathrm{H}_{2} \mathrm{O}$ is observed. In the range from 400 to $450{ }^{\circ} \mathrm{C}$ the oxalate itself decomposes releasing $\mathrm{CO}$ and $\mathrm{CO}_{2}$. Simultaneously a disintegration of CoTMPP occurs. Mass signals, arising from the meso-substituents can be detected as well as nitrogen containg porphyrin ring fragments such as hydrogen cyanide. Raman investigations reveal that this step is responsible for the formation of a carbon based material with high electrochemical activity towards the electro reduction of oxygen. A last mass loss is 
observed above $600{ }^{\circ} \mathrm{C}$ which is correlated to the reduction of iron oxides to elemental iron by carbon. The remaining iron particles are removed by treatment in hydrochloric acid so that a highly porous carbon material is obtained.

The sulfur suppresses the catalytic formation of graphite which usually proceedes in this temperature range. This effect is also known from steel industry [24]. The sulfur is fourfold coordinated to iron which blocks the formation of $\mathrm{Fe}_{3} \mathrm{C}$, which decomposes to metallic iron and graphite at lower temperatures.

Temperatures exceeding $900{ }^{\circ} \mathrm{C}$ finally lead to the loss of the catalytic activity. Since no mass release is observed within this step, we have to conclude that a molecular reconstruction of the material is responsible for this effect.

Tafel-plots of catalytic currents related to the metal content are shown in fig. 2 and illustrate what catalytic quality could be reached as compared to pyrolised metal porphyrin and to an industrial Pt standard. A remarkable fact is that, compared to platinum catalysts the catalytic oxygen reduction current at $0.7 \mathrm{~V}$ can be one order of magnitude higher. A comparison of catalyst behavior at $0.7 \mathrm{~V}$ is justified for rotating disc electrodes, because fuel cell catalysts are typically operated at this potential and diffusion errors are comparatively small. However, compared to the Pt reference the loading with catalytic centers in the range of 3-4\% $\mathrm{Co}-\mathrm{Fe}$ appears to be too low and for some unknown reason it cannot simply be increased by providing a higher metal addition.

For a better control of the synthesis of catalytic centers it is necessary to understand their chemical nature. This may show the way for improved synthetic pathways.

Fig. 3a shows a high resolution TEM picture of the catalyst material $(\mathrm{Co} / \mathrm{Fe} / \mathrm{S})$ and for comparison a standard Pt-catalyst on carbon support (fig. 3b). In contrast to platinum, no metal components are detectable. This is also confirmed by EXAFS studies, where no crystalline phases could be detected in the acid leached catalytic material, measured at the K- 
edges of cobalt and iron. The conclusion must be that the studied non-noble transition metal catalysts have a molecular structure.

To reveal its structure a summary is given in fig. 4 of the components identified by different analytical techniques. XRD and Raman measurements reveal a graphene-graphite network of carbon. EXAFS studies indicate that the identified embedded metal centers have a nitrogen environment (a pyridinic structure was selected for simplicity and not a pyrrolic, which was equally detected in the graphene structure). This means that the metal porphyrin core structure is essentially preserved at pyrolysis temperatures of $750{ }^{\circ} \mathrm{C}$. EXAFS studies confirm furthermore that sulfur is not bound to the metal centers. Information on nitrogen, oxygen and sulfur bonding has also been optained by XPS (not shown). It can be concluded that also here the bonding can be related to the nitrogen-metal structure of porphyrins. Beside this quinone, oxide, amino and carboxyl groups have been detected. Reliable information concerning the oxidation state of our metals could not be obtained because of the low metal content.

Altogether, Raman measurements reveal distorted graphene layers.

The question now arises, how such graphene-based structures can get involved in multielectron transfer, which is evidenced by the high positive potential $(0.7-0.8 \mathrm{~V})$ at which oxygen reduction is still proceeding as well as by the comparatively low contribution of $\mathrm{H}_{2} \mathrm{O}_{2}$ formation $(<10 \%)$. [25] However, it has to be emphasized, that a fraction of the catalytic centers is not involved in a 4-electron transfer to water, but in a 2-electron transfer to hydrogen peroxide. This means that two parallel oxygen reduction pathways are present.

It is known from literature that porphyrin-type $\mathrm{MN}_{\mathrm{x}}$ metal $(\mathrm{M})$ centers do not engage in 4electron multielectron transfer since they generate a lot of hydrogen peroxide. The same is known from quinone-modified glassy carbon. In both cases hydrogen peroxide is the product. From many electrochemical studies and also from biology, it is known that transition-metal dstates must be involved to provide favorable coordination complexes to accommodate several electrons (or positive) charges. Individual centers such as $\mathrm{FeN}_{\mathrm{x}}$ or $\mathrm{CoN}_{\mathrm{x}}$ cannot do that when 
interacting with oxygen, in contrast to noble metals like $\mathrm{Pt}, \mathrm{Ru}, \mathrm{Rh}$, which can engage in peroxo-type of complexes. However, the availability of electronic charge carriers on d-states is not a sufficient condition for oxygen reduction. They must also be engaged in a favorable activation complex liberating oxygen.

Ruthenium particles, being of metallic nature provide large numbers of electrons for reaction. But this property is not sufficient for efficient oxygen reduction catalysis. Availability of electrons is a necessary, but nut sufficient condition for multi-electron transfer catalysis. Oxygen reduction on metallic Ru nano particles only becomes favorable when Se is present on the interface, facilitating in turn a suitable complex for oxygen reduction.

A model to explain the observed mechanism of multi-electron transfer must therefore be searched for in the special nano-structure of the graphite-graphene environment of the $\mathrm{FeN}_{\mathrm{x}} / \mathrm{CoN}_{\mathrm{x}}$ centers. The graphene environment itself, which would be able to supply the necessary charges, can not do this in a catalytically favorable way. It is still present at $950^{\circ} \mathrm{C}$, a temperature, at which catalytic activity has broken down [26].

But in preceding work it was shown that increasing nano-structuring of the $\mathrm{Fe} / \mathrm{Co}-$ graphene/graphite structure improved catalytic activity over-proportional by improving the electrochemically accessible surface area. [17]

Fig. 5 shows the XRD pattern of the $\mathrm{Co} / \mathrm{Fe} / \mathrm{S}$ catalyst and compares it with the well-known reference spectra. Below, the spectrum of a natural graphite (Canadian flake, Timcal) is shown. The practically complete missing of higher reflection order (e.g. $2 \Theta=004)$ can be explained by massive stacking faults in 001 direction. Therefore the peak position of the 002 reflex is shifted to lower $2 \Theta$ values. The full width half maximum of the broadened and small 002 peak (measured with several samples) points to graphite type areas with a particle size in the range of a few $\mathrm{nm}$ and a Van der Waals gap increased to $0.36 \mathrm{~nm}$ due to stacking faults, intercalation or surface effects. The carbon material present in the environment of the 
$\mathrm{Co} / \mathrm{Fe} / \mathrm{S}$-catalyst is consequently graphite with a Van der Waals gap of $0.36 \mathrm{~nm}$, compared to $0.33 \mathrm{~nm}$ found with pure graphite crystals.

For a later discussion Fig. 5 (Timcal) shows, that this gap can, discounting $2 \times 0.077 \mathrm{~nm}$ for the carbon atom radius, still accommodate intercalated species of metal salts such as $\mathrm{FeCl}_{3}$. As demonstrated in [22] Raman studies can provide additional information on the molecular structure of graphene layer.

The Raman spectrum of the reference material "Canadian flake" (shown in Fig. 6a) reveals a pronounced peak at $1581 \mathrm{~cm}^{-1}$ (the so called G-peak) and a less intensive peak at $1336 \mathrm{~cm}^{-1}$. The G-peak is caused by the C-C vibrations of the planar graphene layer, while the D-peak is correlated to the edges of the graphene layer. The intensity ratio of these two peaks gives information about the planar extension of the graphene layer which is calculated by the formula:

$L_{a}=\frac{I_{G}}{I_{D}} \bullet 4.35$

Thereby the "Canadian flake" reveals graphene layers with planar extension of $16 \mathrm{~nm}$.

In contrast to these well-defined and extended graphene layers of the "Canadian flake", the Raman spectrum of Carbon Black is changed. Fig. $6 \mathrm{~b}$ presents the Raman spectrum of our $\mathrm{Co} / \mathrm{Fe} / \mathrm{S}$ catalyst.

In contrast to the "Canadian flake" pattern, the ratio of the intensities $\mathrm{I}_{\mathrm{G}} / \mathrm{I}_{\mathrm{D}}$ is changed so that the planar extension of the graphene layers is reduced to $4.4 \mathrm{~nm}$. Beside these two peaks additional peaks have been detected, which have been correlated to $\mathrm{sp}_{2}$ - hybridized carbon which is not located in the graphene layer (at ca. $1200 \mathrm{~cm}^{-1}$ ) and integrated five-carbon rings in the graphene layer (at ca. $1500 \mathrm{~cm}^{-1}$ ). Probably, the five-carbon rings cause distortions in the graphene layer so that the planar extension is restricted. The distortion is apparently due to the incorporated centers and to the characteristic border regions (compare fig. 4). 
A corresponding structural scheme of the graphene layers is shown in fig 6c. We are consequently dealing with stacks of distorted graphene layers having a typical dimension of $4.7 \mathrm{~nm}$ to $3.6 \mathrm{~nm}$ for pyrolysed CoTMPP (depending on the pyrolysis stage), for $\mathrm{Co} / \mathrm{Fe} / \mathrm{S}$ pyrolysed at $750{ }^{\circ} \mathrm{C}$ the dimension is $4.3 \mathrm{~nm}$. [25] This is in agreement with XRD data.

This determination of the approximate graphite-graphene structure now allows us to narrow down the possible structural alternatives for explaining the multi-electron transfer observed.

The simplified model systems discussed in fig. 7a) to 7c) only consider pyridinic nitrogen for simplicity and because it can be fitted into a graphene layer more easily, even though XPS measurements have shown that pyridinic and pyrrolic nitrogen are coexisting in the catalysts. Nano-graphite can be intercalated with metal salts as indicated in fig. 7a. It is known that intercalation of nano-graphite does not yield the phenomenon of staging [27], which was confirmed in our laboratory by attempting intercalation from fused $\mathrm{FeCl}_{3}$ salt. No XRD signal, expected for staging was obtained. Intercalation maintained the high catalytic quality of the catalyst. The proposed catalytic center of fig. $7 \mathrm{a}$ is a $\mathrm{FeN}_{\mathrm{x}} / \mathrm{CoN}_{\mathrm{x}}$ center in a graphene layer cooperating with an intercalated $\mathrm{Fe} / \mathrm{Co}$ metal center in close vicinity and close to an edge site, which allows exchange of oxygen and protons with the electrolyte.

Since quinone groups attached to the rim of the graphene layers were identified a second type of catalytic center involving one of these quinone groups with a $\mathrm{FeN}_{\mathrm{x}} / \mathrm{CoN}_{\mathrm{x}}$ center within a graphene layer is presented in fig. $7 \mathrm{~b}$.

Both of the two redox components of this second possible multi-electron transfer center alone only reduce oxygen to hydrogen peroxide, but together they may interact in catalyzing a 4electron transfer to yield water from oxygen. There are, however, possible complications. One is the nature of oxygen interaction with this hypothetical binary center and another is the position of the redox potential, which depends on the size of the aromatic ring system. It may also be argued that if quinone/hydroquinone redox centers are active, they should statistically dominate as individual centers. These, however, should flood the catalyst with $\mathrm{H}_{2} \mathrm{O}_{2}$. A 
similar model, but where $\mathrm{Cu}^{2+}$-ions act only as $\mathrm{O}_{2}$ adsorption sites in the neighbourhood of quinone/hydroquinone groups is discussed in reference. [28]

The third possible multi-electron transfer center (fig. 7c) may develop when a $\mathrm{FeN}_{\mathrm{x}} / \mathrm{CoN}_{\mathrm{x}}$ center in a graphene plain interacts with an electron donating metal complex attached to the rim of a graphene layer. In this case, oxygen may attach to the $\mathrm{FeN}_{\mathrm{x}} / \mathrm{CoN}_{\mathrm{x}}$ center and the electron donating metal complex could be linked to the (distorted) porphyrin-metal via back bonding interaction. The back bonding mechanism provides for the necessary interaction to facilitate a rapid concerted additional supply of electrons to the metal center where the $\mathrm{O}_{2}$ molecule reacts to water. Such a peripheral complex must have the capacity to specifically interact with the porphyrin center and there must be a downhill reaction stimulated by an electronic feedback mechanism, which accounts for the required multi-electron transfer. That this is possible has been shown by C. Shi and F. Anson for a cobalt-porphyrin interacting with a peripherically attached Ru-complex. [29] This interaction facilitated a multi-electron transfer.

The question with such a peripherically attached metal complex is whether it can be stable against irreversible oxidation with oxygen. Only very stable complexes may have the ability to maintain a reasonable stability of an oxygen reduction catalyst.

While all three proposed candidates for multi-electron transfer catalysis appear to be theoretically possible we suppose later that the first one (fig. 7a) is the most probable. The main argument is that the bi-metal centers are quite well protected against irreversible oxidation because one metal site is stabilized by the pyridinic (pyrrolic) environment and the second by the graphitic environment on its intercalation position. Molecular oxygen is not expected to convert the bi-metallic center irreversibly to metal oxide. However the electron exchange with this center should be possible. A second argument might be that this bimetallic center very much resembles the biological $\mathrm{Fe}-\mathrm{Cu}$ center of cytochrome oxidase in living organisms, which reduces oxygen to water. Due to metallically conducting graphene 
layers, positioning of 4 positive charges within the bi-metallic center (fig. 7a) is not a problem, since negative counter charges can be displaced and compensated by interfacial electrochemical polarisation.

Several analytical tools were employed to verify the nature of the supposed catalytical center. Fig. 8 shows an EPR-spectrum of a $\mathrm{Co} / \mathrm{Fe} / \mathrm{S}$ catalyst. The material shows similar behaviour to quantum mixed EPR-spin states (5/2 and 3/2) from iron (III) in square planar coordination with a slightly rhombic contribution (in our case: $\mathrm{E} / \mathrm{D} \approx 0.07$ ). [30-31] The spin states appear at $\mathrm{g}$-values of $\mathrm{g}_{\mathrm{y}}{ }^{\text {eff }}=6.1(\mathrm{~S}=5 / 2)$ and $\mathrm{g}_{\mathrm{x}}{ }^{\text {eff }}=4.45(\mathrm{~S}=3 / 2)$. There should also be a contribution of iron $(\mathrm{S}=5 / 2, \mathrm{~S}=3 / 2)$ at $\mathrm{g}_{\mathrm{z}}{ }^{\text {eff }} \approx 2$, which is much smaller than that of $\mathrm{g}_{\mathrm{y}}{ }^{\text {eff }}$, $\mathrm{g}_{\mathrm{x}}{ }^{\text {eff }}$. Kennedy et al. [32] found an unusually large signal in their ( $\mu$-oxo)iron(III) phthalocyanines which additionally showed a hyperfine structure. They had different models for the interpretation of this behaviour, but favoured an antiferromagnetically coupled Fe(III)$\mathrm{O}-\mathrm{Fe}(\mathrm{III})$ moiety in their sample. A comparable hyperfine structure at $\mathrm{g}=2$ can be seen in our catalyst (see the inner graph of Fig. 8) but in our case it is additionally suppressed by the paramagnetic contribution of carbon at $g=2.003$. Related to Kennedy et al. we would not exclude antiferromagnetic coupling. However, mixed spin states may indicate interaction between metallic centers, but additional studies are required. It should further be mentioned that X-band EPR is not sensitive for Fe(II) porphyrin like species because of a large zero field splitting [33], so Fe(II) species cannot be excluded in our catalysts.

Extended X-ray Absorption Fine Structure (EXAFS) measurements are the preferred tool to reveal bonding neighbours, bonding distances and coordination numbers. This technique helped a lot in developing the preparation of this catalyst system [26]. For example it was found that the number of Co-centers, which cannot be leached out with nitric acid decreased with increasing preparation temperature. Between a preparation temperature of $450{ }^{\circ} \mathrm{C}$, when the catalyst did not yet work and the temperature of $750{ }^{\circ} \mathrm{C}$, which generated a very good 
catalyst (fig. 1), the Co - content, after nitric acid treatment, decreased by a factor of three. At $950{ }^{\circ} \mathrm{C}, 75 \%$ of these $\mathrm{CoN}_{\mathrm{x}}$ centers are still present, but the catalytic activity is gone. The presence of Co in a nitrogen- macro-cycle environment is therefore not a sufficient condition for good catalytic properties. But its presence is necessary since their destruction, above 950 ${ }^{\circ} \mathrm{C}$ leads to a break down of catalytic activity. This behavior indirectly suggests that if $\mathrm{MN}_{\mathrm{x}}$ is one of the acting components, the second one, participating with $\mathrm{MN}_{\mathrm{x}}$ shows a different temperature dependency. It is considered as a support for the function of a bi-metallic catalyst.

For pure CoTMPP (fig. 9c), the EXAFS spectrum exhibits peaks originating from the cobaltnitrogen distances (at $1.4 \AA$ ) and cobalt-carbon interactions at higher distances. In contrast the EXAFS spectra of the CoTMPP/ $\mathrm{FeC}_{2} \mathrm{O}_{4} / \mathrm{S}$ (fig. 9a) and $\mathrm{FeTMPPCl} / \mathrm{CoC}_{2} \mathrm{O}_{4} / \mathrm{S}$ (fig. $9 \mathrm{~b}$ ) catalysts only exhibit a single coordination shell. Good agreement with the experimental data can be obtained by fitting the first shell with theoretical calculations for the $\mathrm{Co}-\mathrm{N}$ interaction (fig. 9a and b) obtained by the multiple scattering algorithm FEFF. [23] The absence of higher coordination indicates that, in agreement with fig. 4 and fig. 6c, the metal centers are embedded in a disordered graphite matrix. Further, the resemblance of the Co-edge spectra of the two catalysts indicates that interchange of metal ions from the oxalate precursor into $\mathrm{N}_{\mathrm{x}^{-}}$ centers is possible. Measurements at the Fe-edge showed analogous results for the Fe species (not shown). The introduced sulfur was not found to interact with the catalytic center. For non etched samples EXAFS studies also showed crystallized nanoparticles of transition metal sulfides. These species can easily be removed by an acid-treatment without decreasing the catalytic activity. EXAFS analysis thus helped to narrow down possible candidates for catalytic centers and to show that the catalyst has a molecular and not a nano-particle structure (as also evident from TEM studies fig.3). However, EXAFS information could not give a direct answer with respect to the question of a bi-metallic center as for the diluted catalyst samples it is not sensitive enough to prove neighbors with distances approx. $>4 \AA$. EXAFS 
data are therefore not in contradiction with such a bi-metallic model but also cannot provide a direct proof for a bimetallic center. But there is, as already mentioned, an indirect EXAFS evidence for a binary catalytic center. A second catalytic factor must be generated in a limited higher temperature region, which assists the nitrogen coordinated Co centers in their catalytic activity.

Mössbauer spectroscopy is a very sensitive tool for monitoring the environment of an iron center. Fig. 10b shows the Mössbauer spectrum obtained with the FeTMPPCl porphyrin. An anisotropic doublet is obtained, which is reasonably well understood and has been explained by spin-spin relaxation effects with iron present as a high-spin complex [34]. Fig. 9a shows, for comparison, the Mössbauer spectrum of the $\mathrm{FeTMPPCl} / \mathrm{FeC}_{2} \mathrm{O}_{4} / \mathrm{S}$ catalyst. It contains 3 doublets, one of it, doublet 1 (IS $=0.34 \mathrm{~mm} / \mathrm{s}, \mathrm{QS}=0.85 \mathrm{~mm} / \mathrm{s}$ ), is common to all catalyst spectra and may be attributed to a $\mathrm{FeN}_{\mathrm{x}}$ coordination within a distorted graphit/graphene environment [26].

A remarkable property of the oxygen reduction catalyst, based on abundant transition metals, is that the transition metals can be exchanged and that they can be introduced, both, via the porphyrin and the metal oxalate.

This may indicate that non-porphyrin metals reach a close vicinity to the $\mathrm{MN}_{\mathrm{x}}$ centers $\left(M=\right.$ metal) and that porphyrin metals leave the $N_{x}$ environment and may stay somewhere in the vicinity. This would support a bi-metallic reaction center, as indicated in fig. 7a.. Tafel plots of catalytic activity, referred to the metal content, obtained for combinations of $\mathrm{Co}, \mathrm{Cu}$, $\mathrm{Mn}, \mathrm{Fe}$, with $\mathrm{Fe}$ are shown in fig. 11. While the same $\mathrm{FeC}_{2} \mathrm{O}_{4}$ and the same sulfur source were applied for the catalyst preparation under exactly identical conditions, the porphyrins were exchanged with respect to the metals between $\mathrm{Co}, \mathrm{Cu}, \mathrm{Mn}$ and $\mathrm{Fe}$. These experiments concentrate on iron oxalate, because other oxalates will lead to other morphologies and thus electrochemical transport properties of the catalysts which may complicate the discussion. Previous studies [17] have shown that a change to oxalates of Ni, Co, Sn strongly affected the 
nano-morphology of the catalysts, and thus transport parameters. This should be avoided in fig. 11. It is remarkable that the open circuit potential $(\sim 0.9 \mathrm{~V})$ remains surprisingly constant indicating a comparable energetic behavior of the catalyst material. Kinetically there are differences: the kinetic current at $0.7 \mathrm{~V}$ varies from $0.15 \mathrm{~A} / \mathrm{mg}$ with $\mathrm{MnTTPCl}$ and CuTTP to $0.9 \mathrm{~A} / \mathrm{mg}$ with CoTMPP, respectively. It is seen that, while the catalytic activity observed is different it stays within the same order of magnitude. This indicates similar properties. Some substitution of $\mathrm{Cu}$ and $\mathrm{Mn}$ by $\mathrm{Fe}$ in the $\mathrm{N}$ coordination is expected. But the difference in current density observed clearly shows that we are not dealing with identical catalysts. It may be concluded that exchange of metals will only have been partial. More sophisticated analytical techniques will have to be applied in the future for a more detailed analysis of catalytic reactivity. Most important is the observation that the open circuit potentials reached, reflecting thermodynamic forces, are comparable in size, which testifies for similar energetic properties, while the mechanism itself may involve a complex set of electrochemical steps. Interestingly, also the iron only catalyst works as a multi-electron transfer catalyst.

\section{Discussion:}

The investigated catalysts based on abundant transition-metals do not work like the nanosized Pt-particle catalysts. The catalytic centers have a molecular structure, which is integrated in a graphit-graphene nano environment. The suggested bi-metallic centers are largely protected within this environment against irreversible oxidation. The obtained analytical experimental data (XRD, RAMAN, EPR, EXAFS, XPS, Mössbauer spectroscopy) project a quite complex image of the oxygen reduction catalyst. XRD and RAMAN measurements highlight the significance of the graphene structure. EXAFS excludes crystallized catalytic centers and shows, that $\mathrm{CoN}_{\mathrm{x}}$ or $\mathrm{FeN}_{\mathrm{x}}$ alone, which are threefold more concentrated in catalysts prepared at $450{ }^{\circ} \mathrm{C}$ compared to catalysts prepared at $750{ }^{\circ} \mathrm{C}$ are not generating high catalytic activity. 
An additional chemical-structural factor has to be activated above $700{ }^{\circ} \mathrm{C}$. XPS (data not shown in this work) was helpful in confirming the nature of nitrogen in the catalytic centers, but turned out to be too insensitive for reliable measurements of metal concentrations in catalysts after treatment with acid for high performance. Mössbauer Spectroscopy of $\mathrm{Co} / \mathrm{Fe} / \mathrm{S}$ shows next to Doublet 1 two more doublets in contrast to the asymmetric doublet related to iron porphyrins, but the determined structure is similar to other porphyrin based heat treated catalysts [9], and materials with a $\mathrm{MN}_{\mathrm{x}}$ structure [30]. Theoretical research and model experiments will be required to find out more about the nature of these centers. EPR data visualizes the paramagnetic resonance of the nitrogen coordinated catalytic centers.

All the experimental data are in agreement, or at least not in contradiction with the concept of a bi-metallic catalyst as proposed in fig. 7a-c.

When the catalytic model of fig. $7 \mathrm{~b}$ is discarded because of oxygen binding complications and because of high $\mathrm{H}_{2} \mathrm{O}_{2}$ yield expectations from individual quinone-hydroquinone centers, the two alternatives, fig. 7a and 7c, remain. They involve 2-metal centers each. However, their catalytic mechanism is drastically different. In the first case (fig. 7a) we are, for example, dealing with a cooperative reaction between an iron center in $\mathrm{N}_{4}$ environment and an intercalated $\mathrm{Cu}$-ion as indicated in fig. 12a. The position of intercalated $\mathrm{Cu}$ is likely to be distributed statistically within the nano-graphitic environment, but there is a probability that $\mathrm{Cu}$ centers will be available near the $\mathrm{FeN}_{\mathrm{x}}$ centers. For comparison, the oxygen-reducing $\mathrm{Fe}-$ $\mathrm{Cu}$ center of the cytochrom oxidase is shown in fig. 12c. It is nearly identical. The iron is surrounded by the $\mathrm{N}$-atoms of a heme molecule; three histidine molecules are fixing the copper ion. The oxygen molecules interact with the two metal centers extracting electronic charge. A proton and an electron are added to yield an oxygen atom attached to $\mathrm{Fe}^{\mathrm{IV}}$ and an $\mathrm{OH}$ group attached to $\mathrm{Cu}^{\mathrm{II}}$. An additional proton and an electron is added to yield $\mathrm{OH}$-groups attached to both, $\mathrm{Fe}^{\mathrm{IV}}$ and $\mathrm{Cu}^{\mathrm{II}}$ before two additional electrons are added for release of $2 \mathrm{OH}^{-}$ for water formation. The $\mathrm{Cu}$-hystidine-environment in the cytochrome oxidase is obviously 
different from the supposed intercalated $\mathrm{Cu}$ environment in the studied $\mathrm{Fe} / \mathrm{Cu}$ catalyst. This is also indicated by the finding that the studied abundant-transition-metal catalysts are tolerant against $\mathrm{CO}$, but the biological $\mathrm{Fe} / \mathrm{Cu}$ catalyst is not. Our tentative explanation for this discrepancy is the following: Statistically, and depending on the specific chemical character of the environment, there will be a certain distribution in the quality of catalytic sites. There will be some ideal reaction centers and such ones which are modified by distortions of chemical bonds, by the vicinity of structural defects or by adsorbed species. During pyrolysis and carbonization so much carbon monoxide is liberated, between 400 and $450{ }^{\circ} \mathrm{C}$ from oxalate, that all centers which are irreversibly reacting with $\mathrm{CO}$ will be blocked. Only those, which do not strongly bind, or which do not interact at all with $\mathrm{CO}$ will remain active as oxygen reaction centers. They stay experimentally active for oxygen reduction and they may be the only centers involved in catalytic activity. The catalyst structure of fig.7a, may, for example, be stable against $\mathrm{CO}$, because the second metal center is positioned in the Van der Waals gap between graphite layers, where the carbon atoms (of $\mathrm{CO}$ ) with their twice as large ionic radius compared to oxygen, may not enter. The difference in catalyst structure compared to cytochrome oxidase (fig. 12c), may therefore explain the remaining $\mathrm{CO}$ tolerance (after carbonization). If this hypothesis is valid, the same centers may be even more catalytic in absence of a $\mathrm{CO}$ releasing and poisoning pyrolysis treatment. To avoid this problem there have been efforts to substitute oxalates by other salts (without release of $\mathrm{CO}$ ) but up to know preparation of highly active catalyst materials was not successful.

The catalyst model of fig. 7c would not work very differently from that model given in fig. 7a. The best reference would be molecular electrochemical experiments as performed by Anson and coworkers. [25] Here, a cobalt porphyrin only worked as a 2-electron catalyst until Ru-complexes were attached peripherically to the porphyrin structure. A back-bonding mechanism provided for the necessary interaction to facilitate a rapid concerted additional supply of electrons to the cobalt center where the $\mathrm{O}_{2}$ molecule reacted to water. In our case 
the theoretically calculated feedback activated mechanism [19-20] is expected to operate. Such a peripheric complex must have the capacity to specifically interact with the porphyrin center and there must be a downhill reaction stimulated by an electronic feedback mechanism, which accounts for the required multi-electron transfer. The Anson experiments were based on ruthenium complexes supplying a cobalt porphyrin with electrons. Would a non-noble transition metal like Fe behave similar to ruthenium? There is obviously more experimental and theoretical work needed to understand such donor-stimulated multi-electron transfer via $\mathrm{MN}_{4}$ centers (fig. 7c). For the moment $\mathrm{N}_{4-}$ and intercalation- protected centers of abundant transition metals (fig. 7a) in a mechanism similar to that exploited by nature in oxygen reduction are the favored model for the catalytic reaction discussed here.

Transition metal (Co), carbon and nitrogen containing catalysts produced by sputtering by Yang et al [16] produced hydrogen peroxide with $60-80 \%$ yield, indicating that multi-electron transfer is not working. The catalysts discussed here generated hydrogen peroxide with less than $10 \%$, indicating that most catalytic centers have multi-electron transfer properties.

Our model is, by the way, in clear contradiction to a model proposed by Dodelet's group for a $\mathrm{FeN}_{\mathrm{x}}$ only catalyst, which also shows an efficient multi-electron reduction of oxygen with negligible $\mathrm{H}_{2} \mathrm{O}_{2}$ production. [35] It was obtained by heat treatment (at $850-1000{ }^{\circ} \mathrm{C}$ ) in $\mathrm{NH}_{3}$ of carbon black with iron acetate. It is proposed that $\mathrm{FeN}_{4}$ centers only form in pores of width $<22 \AA$ apparently bridging two pore walls. This is deduced from the observation that material has to be volatilized until an optimal micropore area is yielded. These individual $\mathrm{FeN}_{4}$ centers were proposed to be responsible for the multi-electron transfer catalysis.

The authors of the present paper perceive a multi-electron reduction of oxygen to water via individual $\mathrm{Fe}-\mathrm{N}_{4}$ centers as improbable, because it has not been observed with individual metal porphyrin molecules nor has nature been able to evolve such Fe-centers. Even the iron only hydrogenase of Clostridium bacteria needs 2 iron centers (supported by $\mathrm{Fe}_{4} \mathrm{~S}_{4}$ ferredoxin) for the much simpler proton reduction to hydrogen. If $\mathrm{FeN}_{\mathrm{x}}$ centers would, on the 
other hand, work as multi-electron transfer catalysts for oxygen reduction, they should, in principle also work attached to metal surfaces. In such an environment they are, however, known to react via the hydrogen peroxide path, which is not desirable.

On the basis of our hypothesis on multi-electron transfer [19-20] it is expected that also in the catalyst of Dodelet's group at least two centers, including $\mathrm{FeN}_{4}$, are involved. The limiting process requiring material consumption at high temperature appears to be the $\mathrm{FeN}_{4}$ centers synthesized from carbon and $\mathrm{NH}_{3}$ while additional centers from carbonized Fe-oxalate on carbon black were already present. During the preparation, by the authors, of this paper, on the other hand, $\mathrm{FeN}_{4}$ or $\mathrm{CoN}_{4}$ centers were readily introduced into the catalyst but nanographite-graphene for hosting the second center (intercalated or peripherically attached as a metal complex) has, with our catalysts, to be produced at elevated temperature, which is required for obtaining an efficient catalyst.

However, Dodelet's group reported a linear increase of catalytic activity with the iron content [36]. This is an intriguing and very interesting result, which might be explained with our postulated model in fig $7 \mathrm{~b}$. In this case the increased amount of metal would linearly affect the current density.

The over all discussion shows that further approaches are necessary to better understand these catalysts based on abundant transition metals theoretically.

\section{Acknowledgement}

The authors have based their considerations on a wide range of experimental and theoretical information helpfully provided from the entire research group and especially by Drs P. Bogdanoff, S. Fiechter, G. Schmithals, C. Barkschat and I. Hermann. 
$\underline{\text { References: }}$

[1] B. Wang, J. Power Sources 152 (2005) 1.

[2] H.M. Holden, B.L. Jacobson, J. K. Hurley, G. Tollin, B.-H. Oh, L. Skjeldal, Y.K. Chae, H. Cheng, B. Xia, J.L. Markley, J. Bioenerg. Biomembr. 26 (1994) 67.

[3] R. Jasinski, Nature 201 (1964) 1212.

[4] H. Jahnke, M. Schönborn, G. Zimmermann, Top. Curr. Chem. 61 (1976) 133.

[5] K.A., Rudyushkina, J. Research Inst. Catal. Hokkaido Univ. 30 (1982) 155.

[6] K.A., Rudyushkina, M.R. Tarasevich, Russ. J. Electrochem. 22 (1986) 1155.

[7] J.A.R. van Veen, J.F. van Baar, K.J. Kroese, J. Chem. Soc. Faraday Trans. 177 (1981) 2827.

[8] D. Scherson, A.A. Tanaka, S.L. Gupta, D. Tryk, C. Fierro, R. Holze, E.B. Yeager, R.P. Lattimer, Electrochim. Acta 31 (1986) 1247.

[9] J. Blomquist, H. Lang, R. Larsson, A. Widelöv, J. Chem. Soc. Faraday Trans. 88 (1992) 2007.

[10] G. Faubert, G. Lalande, R. Cote, D. Guay, J.P. Dodelet, L.T. Weng, P. Bertrand, G. Denes, Electrochim. Acta 41 (1996) 1689.

[11] S. Gupta, D. Tryk, S.K. Zecevic, W. Aldred, D. Guo, R.F. Savinell, J. Appl. Electrochem. 28 (1998) 673.

[12] A.L. Bouwkamp-Wijnoltz, W. Visscher, J.A.R. van Veen, S.C. Tang, Electrochim. Acta 45 (1999) 379.

[13] M. Bron, J. Radnik, M. Fieber-Erdmann, P. Bogdanoff, S. Fiechter, J. Electroanal. Chem. $535(2002) 113$.

[14] R. Bashyam, P. Zelenay, Nature 443 (2006) 63.

[15] P. H. Matter, E. Wang, M. Arias, E. J. Biddinger and U. S. Ozkan, J. Mol. Cat. A: Chemical 264 (2007) 73. 
[16] R.Yang, A.Bonakdarpour, E. Bradley-Easton, P.Stoffyn-Egli, J. Dahn, J.

Electrochem.Soc. 154 (2007) A275.

[17] P. Bogdanoff, I. Herrmann, M. Hilgendorff, I. Dorbandt, S. Fiechter, H. Tributsch, J.

New Mater. Electrochem Syst. 7 (2004) 85.

[18] M. Hilgendorff, I. Dorbandt, H. Schulenburg, M. Bron, S. Fiechter, P. Bogdanoff, H. Tributsch, Hahn-Meitner-Institut Berlin, Patent No. US2004236157, WO03004156 (2004).

[19] L. Pohlmann, H. Tributsch, J. Theor. Biol. 155 (1992) 443; J. theor. Biol. 156 (1992) 63; in „On Self-Organization“, Springer Series in Synergetics, (Eds: R.K. Mishra, D. Maaß, E. Zwierlein) Springer Verlag, Berlin-Heidelberg, Vol. 61 (1994) 133L. ; Electrochim. Acta 42 (1997) 2737.

[20] H. Tributsch, L. Pohlmann, Chem. Phys. Lett. 188 (1992) 338; J. Electroanal. Chem. 396 (1995) 53; J. Electroanal Chem. 438 (1997) 37; Science 279 (1998) 1891.

[21] K.C. Neyerlin, W. Gu, J. Journe, H. Gasteiger, J. Electrochem.Soc. 153 (2006) A1955.

[22] F. Tuinstra, J.L Koenig, J. Chem. Phys. 33 (1970) 1126.

[23] J.J. Rehr, R.C. Albers, Rev. Mod. Phys. 72 (2000) 621.

[24] H.J. Grabke, D. Moszynski, E.M. Müller-Lorenz, A. Schneider, Surface and Interface Analysis 34 (2002) 369.[25] I. Herrmann, PhD Thesis (2006), Freie Universität Berlin.

[26] G. Schmithals, PhD Thesis (2006), Freie Universität Berlin

[27] T. Enoki, J. Phys.Chem. Sol. 65 (2004) 103.

[28] Y. Nabae, I. Yamanaka, K. Otsuka, Appl. Catal. A280 (2005) 149.

[29] C. Shi, F.C. Anson, Inorg. Chim. Acta 225 (1994) 215.

[30] V. Schünemann, M. Gerdan, A.X. Trautwein, N. Haoudi, D. Mandon, J. Fischer, R. Weiss, A. Tabard, R. Guilard, Angew. Chem. Int. Ed. 38 (1999) 3181.

[31] M.M. Maltempo, M.E. Eberhart, Chem. Phys. Lett. 108 (1984) 204.

[32] B.J Kennedy, K.S. Murray, P.R. Zwack, H. Homborg, W. Kalz, Inorg. Chem. 24 (1985) 3302. 
[33] S. Subramanian, Electron paramagnetic resonance spectroscopy of porphyrins and metalloporphyrins (1975) pp.555-588 in: Porphyrins and Metalloporphyrins, edited by K.M. Smith, ISBN: 0-444-41375-8.

[34] C. Maricondi, D.K. Straub, L.M. Epstein, J. Am. Chem. Soc. 94 (1972) 4157.

[35] F. Jaouen, M. Lefevre, J.-P. Dodelet, M. Cai; paper presented at6 the 5th International Conference on Electrocatalysis, 10-14 September 2006, Kotor, Montenegro.

[36] F. Jaouen, J.-P- Dodelet, Electrochim. Acta 52 (2007) 5975. 
Figure captures:

Fig. 1 Thermogravimetric behaviour of $\mathrm{Co} / \mathrm{Fe} / \mathrm{S}$-catalyst. The lower and higher temperature limits for optimal catalyst performance are indicated.

Fig. 2 Tafel plots comparing pyrolysed CoTMPP/BP, CoTMPP/ $/ \mathrm{FeC}_{2} \mathrm{O}_{4} / \mathrm{S}$ and Platinum/C.

Fig. 3 TEM pictures, comparing nanostructure of $\mathrm{CoTMPP} / \mathrm{FeC}_{2} \mathrm{O}_{4} / \mathrm{S}$ (fig. 3a) and $\mathrm{Pt} / \mathrm{C}$ (fig. 3b).

Fig. 4 Molecular environment of the $\mathrm{CoTMPP} / \mathrm{FeC}_{2} \mathrm{O}_{4} / \mathrm{S}$ catalyst as evidenced on the basis of Raman, XRD, EXAFS and XPS measurements.

Fig. 5 XRD measurements of amorphous and graphitic carbon. The $\mathrm{Co} / \mathrm{Fe} / \mathrm{S}$ catalyst and natural graphite (Canadian flake, Timcal) are compared with the JCPDS reference spectra.

Fig. 6 Raman spectra of graphitic and amorphous carbon: (a) natural graphite ("Canadian flake" from Timcal); (b) $\mathrm{Co} / \mathrm{Fe} / \mathrm{S}$-catalyst and (c) deduced model of graphene layer of pyrolyzed CoTMPP

Fig. 7 Discussed models for multi-electron transfer in Fe/Co-type catalysts: (a) $\mathrm{CoN}_{4}$ plus intercalated $\mathrm{FeCl}_{2}$ near graphite edge, (b) $\mathrm{CoN}_{4}$ interacting with terminal quinone/hydroquinone group on graphene layer and (c) $\mathrm{CoN}_{4}$ - or $\mathrm{FeN}_{4-}$ center interacting with peripheral Fe-complex promoting stimulated electrons transfer.

Fig. 8 X-band EPR spectra of $\mathrm{Co} / \mathrm{Fe} / \mathrm{S}$-catalyst, $\mathrm{g}=6.1$ is due to $\mathrm{Fe}(\mathrm{III})$ in high spin state $(\mathrm{S}=5 / 2)$ and $\mathrm{g}=4.45$ due to $\mathrm{Fe}(\mathrm{III})$ mid $\operatorname{spin}(\mathrm{S}=3 / 2)$.

Fig. 9 Fourier transformed EXAFS spectra (magnitude and imaginary part) for (a) $\mathrm{CoTMPP} / \mathrm{FeC}_{2} \mathrm{O}_{4} / \mathrm{S}$ catalyst, (b) $\mathrm{FeTMPPCl} / \mathrm{CoC}_{2} \mathrm{O}_{4} / \mathrm{S}$ catalyst and (c) CoTMPP precursor; dotted lines: experimental data, solid lines: first shell fit using one FEFF path for Co-N distance. 
Fig. 10 Mößbauer spectra for (a) FeTMPPCl/FeC $\mathrm{F}_{2} \mathrm{O}_{4} / \mathrm{S}$-catalyst and (b) FeTMPPClporphyrin.

Fig. 11 Comparison of Tafel plots related to metal loadings for oxygen reduction behavior observed for different $\mathrm{Fe}, \mathrm{Co}, \mathrm{Cu}, \mathrm{Mn}$ catalysts $\left(\mathrm{FeC}_{2} \mathrm{O}_{4}\right.$ and the sulfur source remained the same).

Fig. 12 Comparison of structural model for (a) proposed $\mathrm{FeN}_{4} / \mathrm{Cu}$ catalytic center with intercalated $\mathrm{Cu}$-ion, (b) alternative $\mathrm{FeN}_{4}$ - center with lateral Co-complex for the induction of stimulated electron transfer to oxygen and (c) $\mathrm{FeN}_{4} / \mathrm{Cu}$ catalytic center of cytochrome oxidase. 


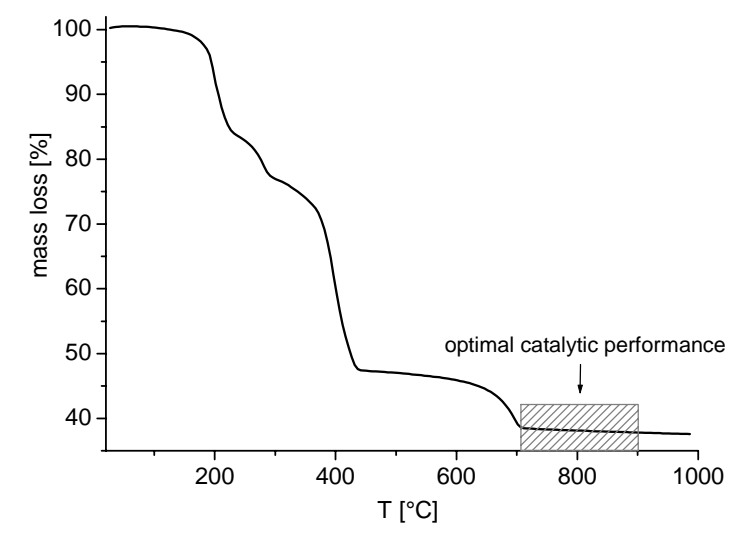

Fig. 1

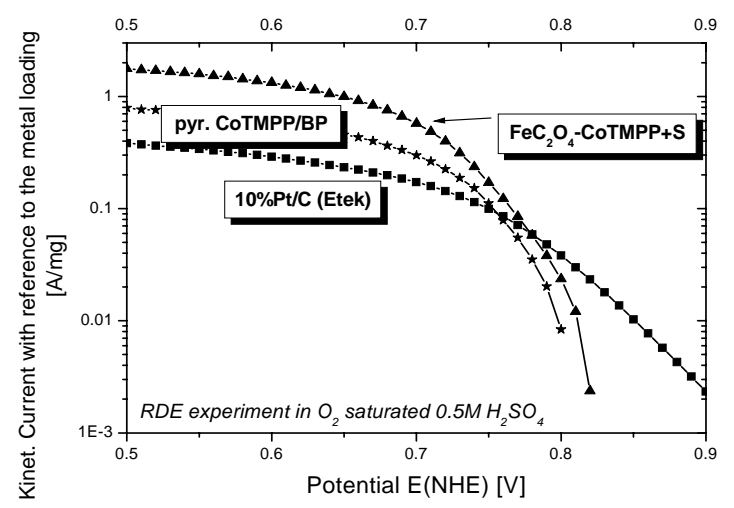

Fig. 2 


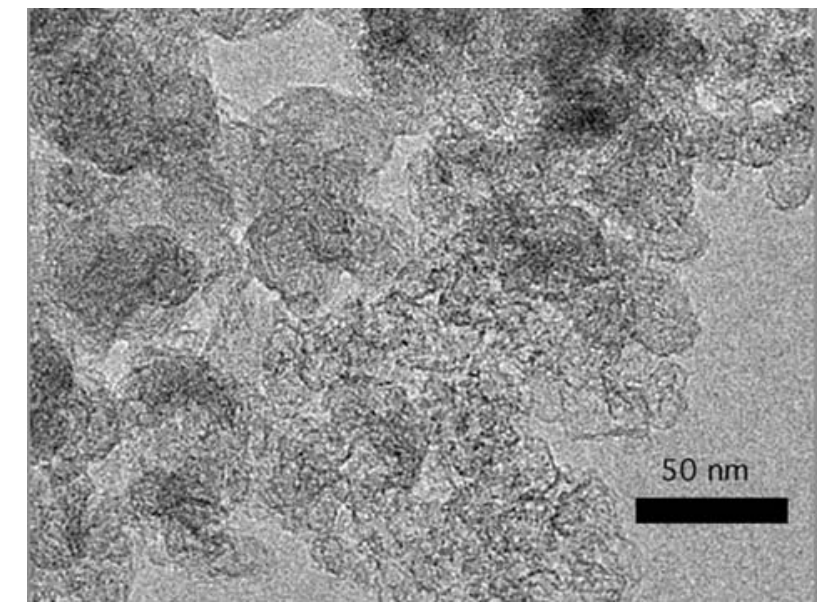

Fig. 3 a) TEM image of a $\mathrm{Co} / \mathrm{Fe} / \mathrm{S}$ catalyst

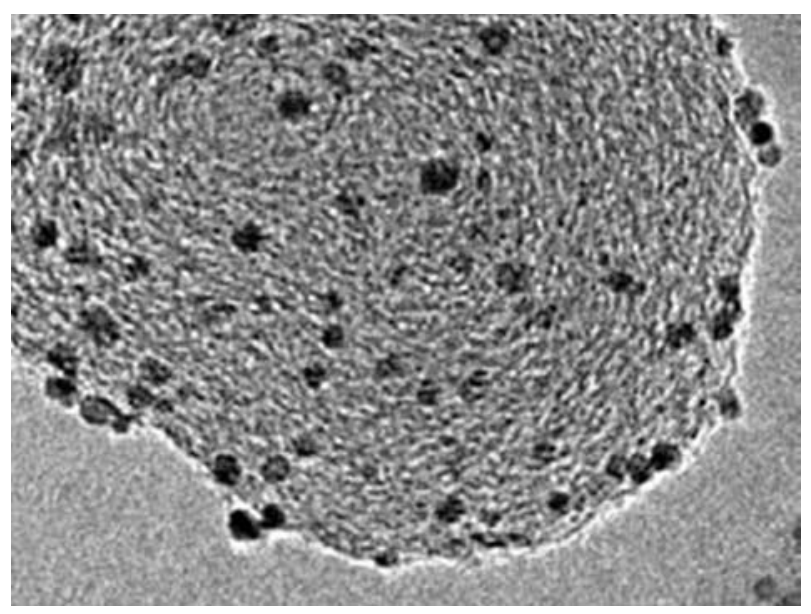

Fig. 3 b) TEM image of a commercial Pt/C catalyst 


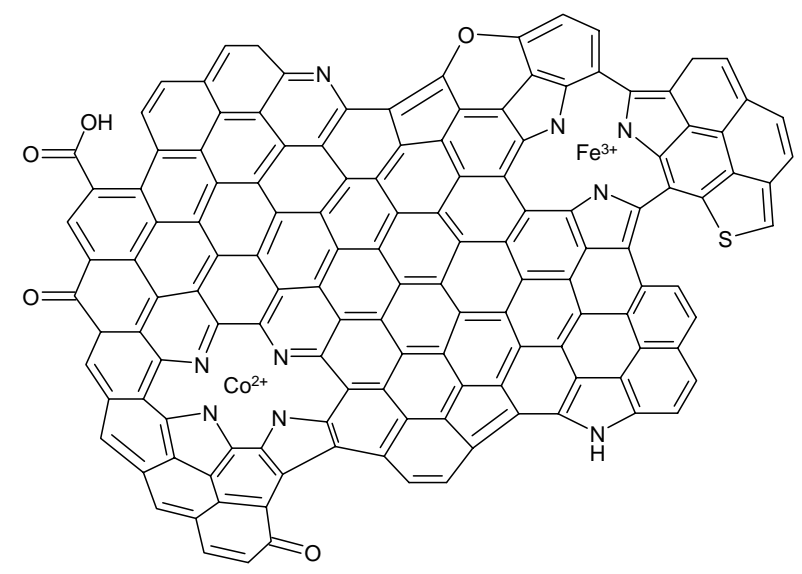

Fig. 4

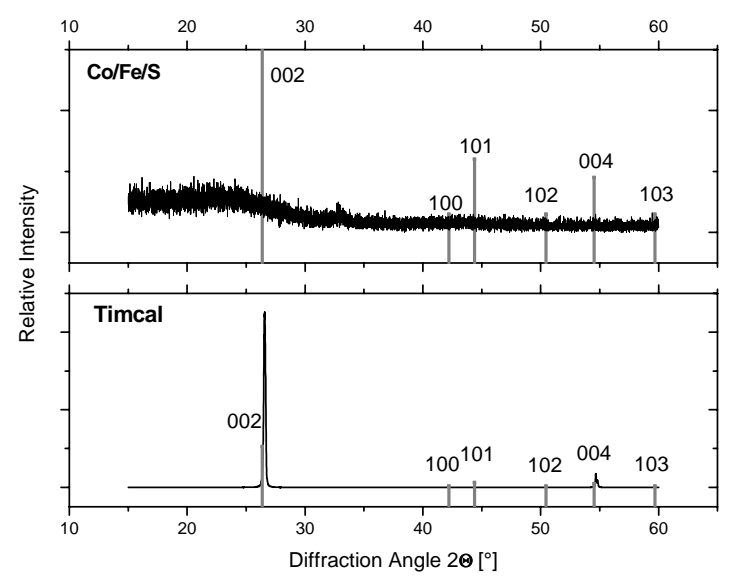

Fig. 5 


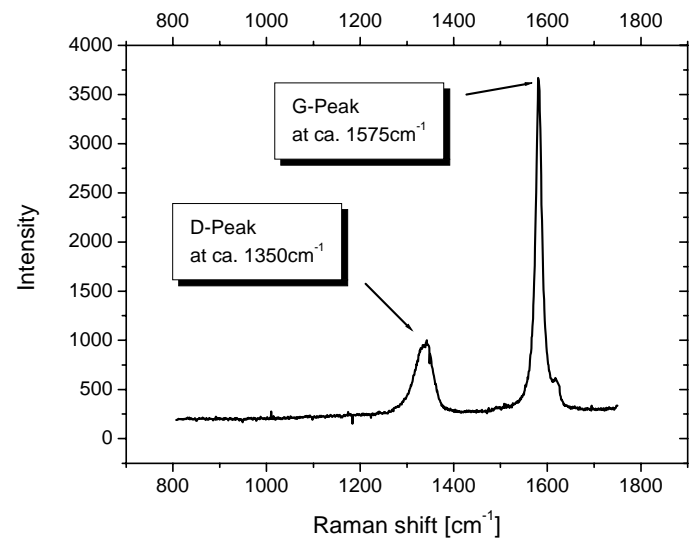

Fig. 6a

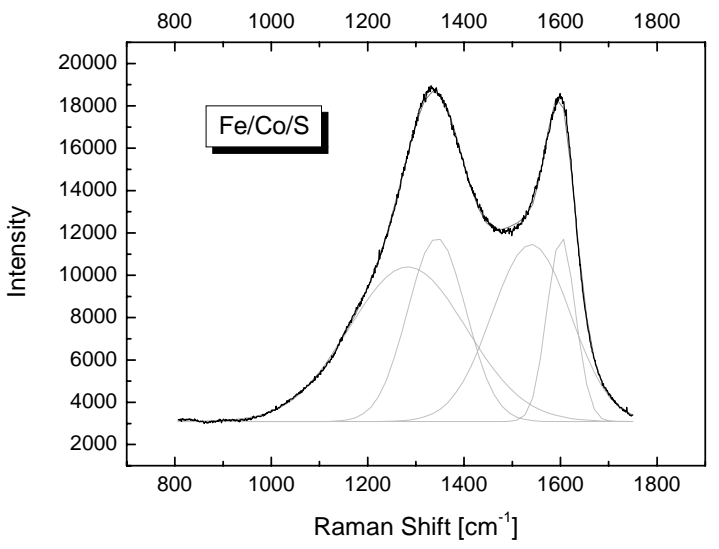

Fig. 6b 


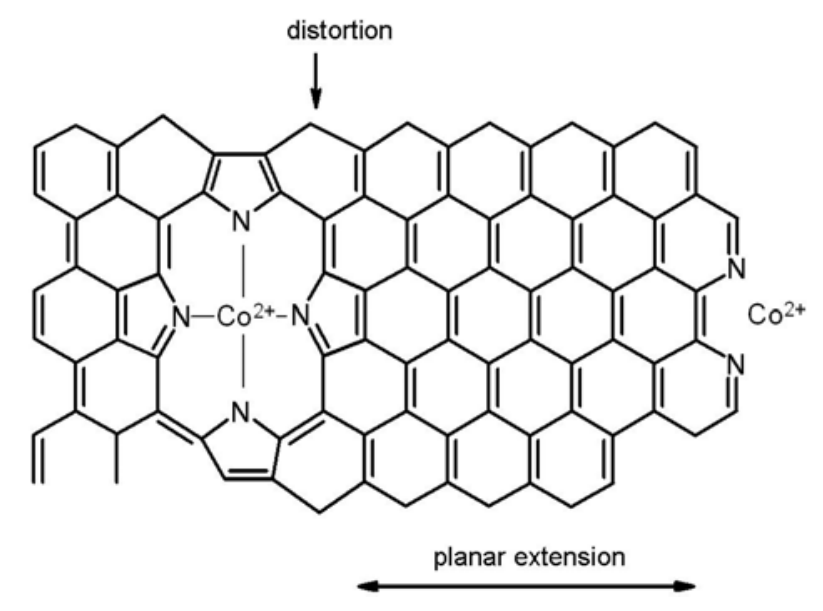

Fig. 6c

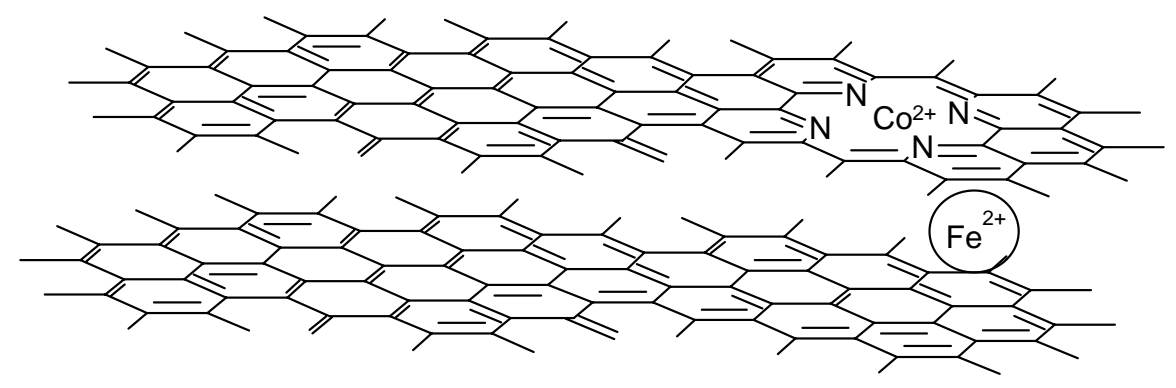

Fig. $7 \mathrm{a}$ 


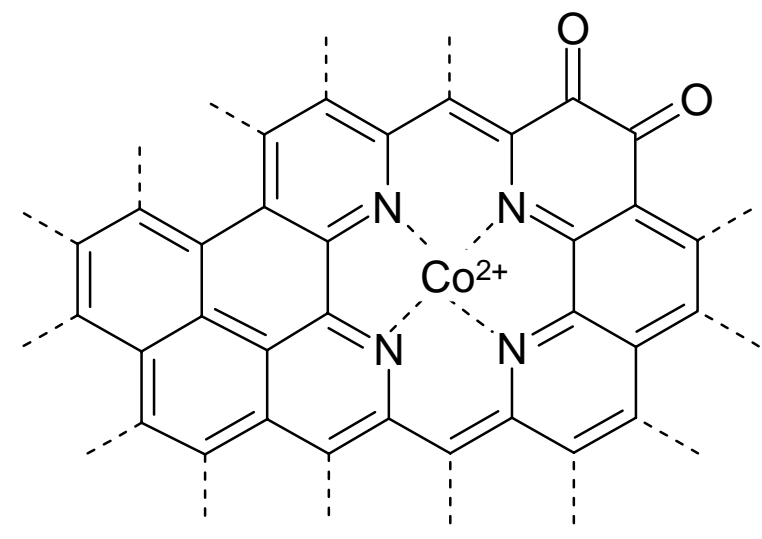

Fig. $7 b$
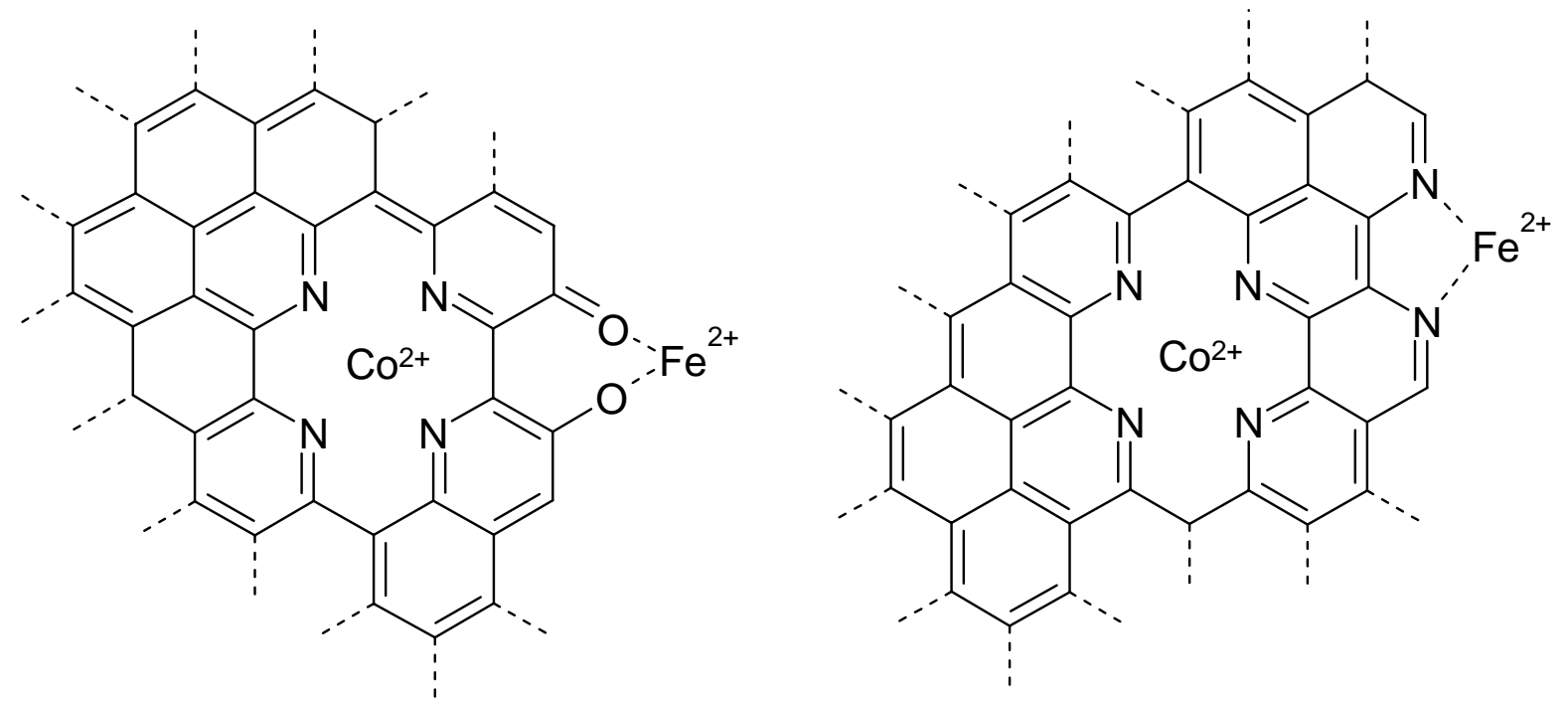

Fig. 7c 


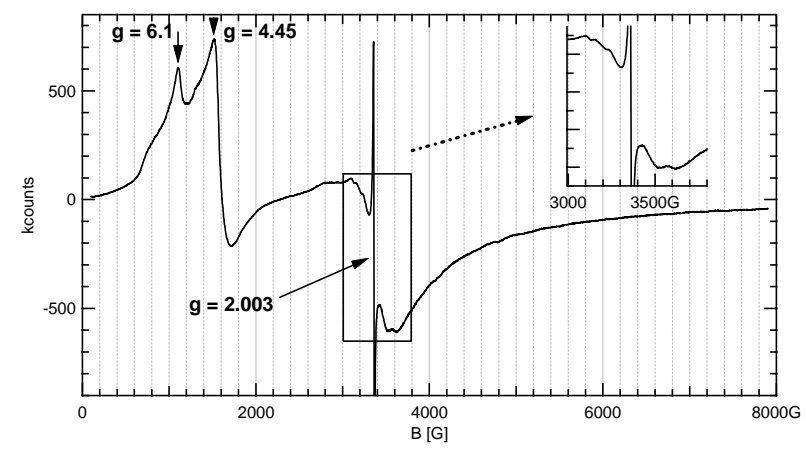

Fig. 8

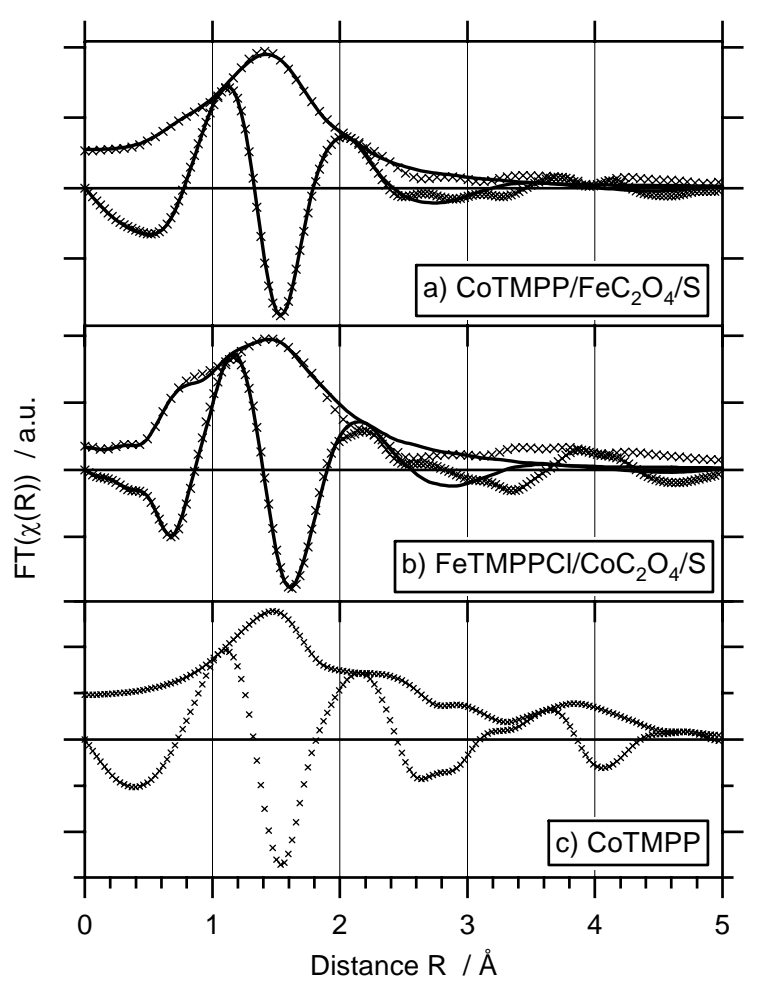

Fig. 9 


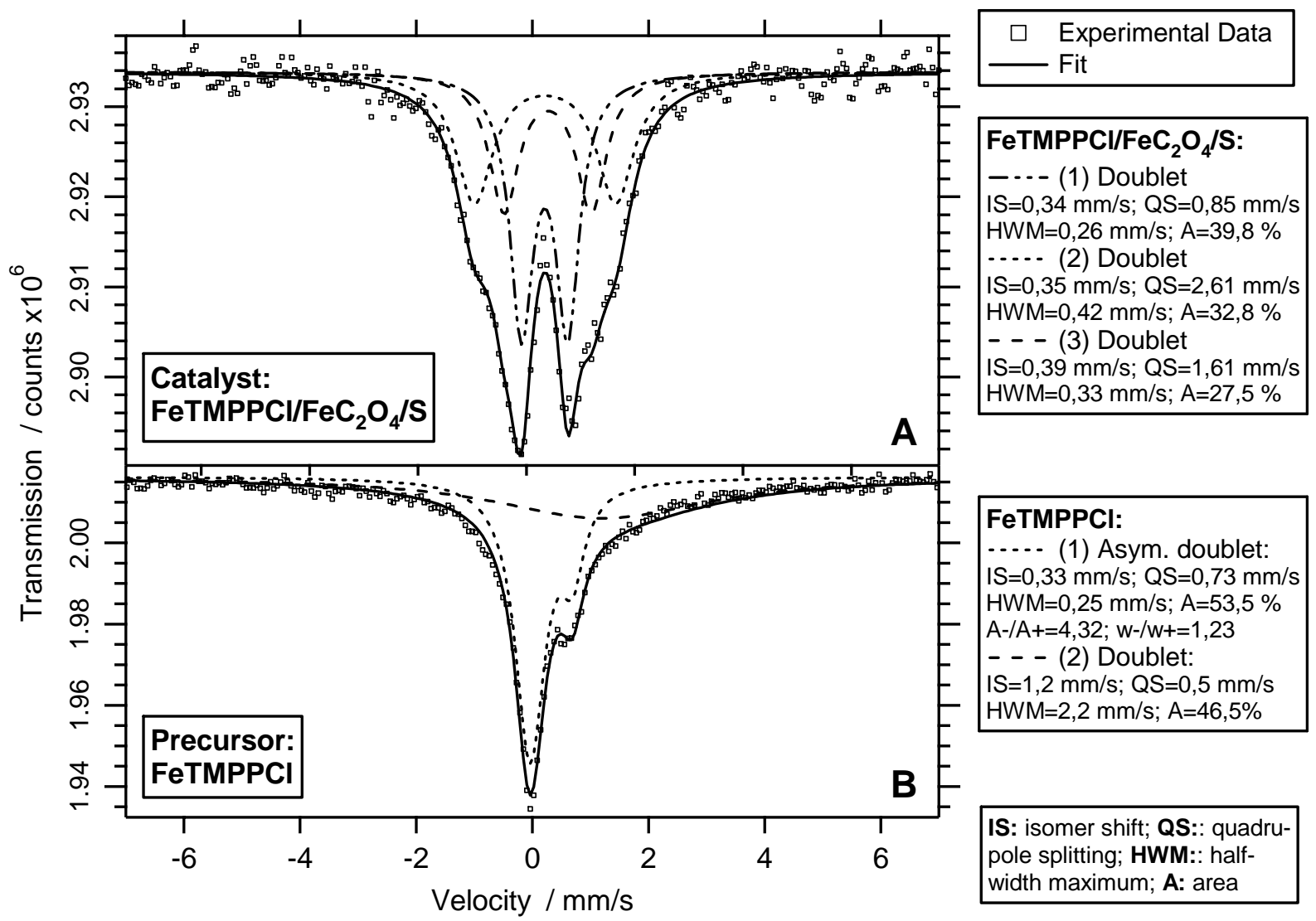

Fig. 10

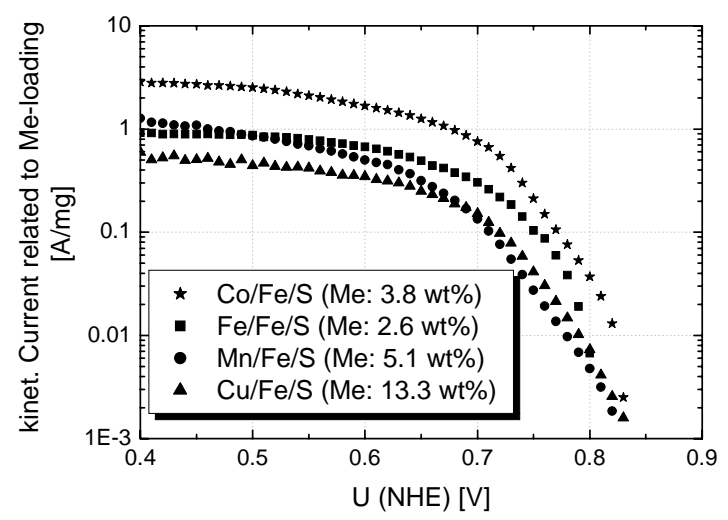

Fig. 11

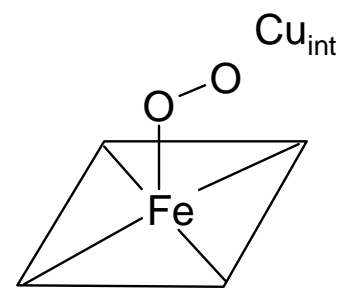


Fig. 12a

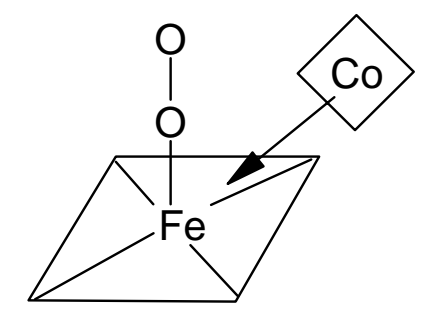

Fig. 12b

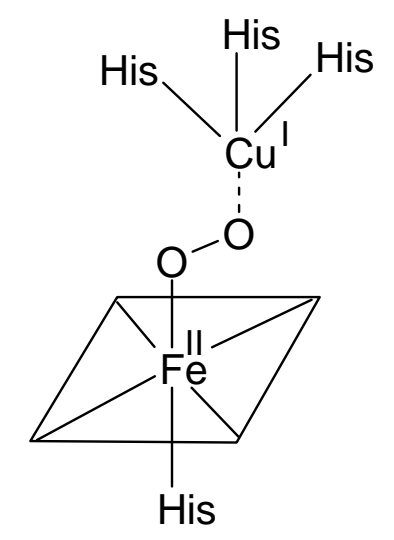

Fig. 12c 